\title{
The effectiveness of an online, distance-learning Master's in Surgical Sciences programme in Malawi
}

\author{
P J W Smith, ${ }^{1} \mathrm{PhD} ;$ O J Garden, ${ }^{1} \mathrm{MD} ; \mathrm{S}$ J Wigmore, ${ }^{1} \mathrm{MD} ;$ E Borgstein, ${ }^{2} \mathrm{MD} ; \mathrm{D}$ Dewhurst,${ }^{3} \mathrm{PhD}$ \\ ${ }^{1}$ Department of Clinical Surgery, College of Medicine and Veterinary Medicine, University of Edinburgh, UK \\ ${ }^{2}$ Department of Surgery, Queen Elizabeth Central Hospital, Blantyre, Malawi \\ ${ }^{3}$ Learning Technology Section, College of Medicine and Veterinary Medicine, University of Edinburgh, UK
}

Corresponding author: PJ W Smith (paula.smith@ed.ac.uk)

\begin{abstract}
Background. Postgraduate surgical training is limited in Malawi, one of the world's poorest countries, and doctors who pursue further training abroad may fail to return. One solution is to deliver education online, allowing trainees to complement their in-the-workplace learning.

Objective. To evaluate the perceived effectiveness of an online MSc in Surgical Sciences programme for trainees continuing to train and work full time in their Malawian clinical environment.

Methods. Twenty-four Malawian surgical trainees enrolled on the programme since 2010. Students' perspectives regarding the MSc were explored by questionnaires, and Malawian student performance was measured using a variety of metrics and compared with that of other students in their year. Training programme supervisors in Malawi were surveyed on their opinions of the effectiveness of the programme.

Results. Feedback revealed that students valued the structured presentation of the basic sciences integrated into interactive virtual patients, the access to e-journals and the opportunity for discussion with international surgical colleagues. Academic performance of Malawian trainees was comparable with that of the cohort average in the first 2 years of the programme. Attitudes of students and supervisors regarding the educational benefits of the programme were positive.

Conclusions. The MSc in Surgical Sciences provides a culture of studying and sharing knowledge with peers and mentors globally, and has increased the academic support network for Malawian trainees from a few dedicated surgeons in the country to an international network. This innovative approach can serve as a model in other developing countries with critical shortages of healthcare workers.
\end{abstract}

Afr J Health Professions Educ 2018;10(3):159-165. DOI:10.7196/AJHPE.2018.v10i3.1020

Less than half of the world's population has access to safe, affordable and timely surgical care. ${ }^{[1,2]}$ In $2010,30 \%$ of all deaths (16.9 million) worldwide resulted from conditions requiring surgical care; this number surpassed that of HIV/AIDS, tuberculosis and malaria combined. ${ }^{[3]}$ The Lancet Commission on Global Surgery identified that the unmet need is greatest in sub-Saharan Africa, where $90 \%$ of the population do not have access to basic surgical procedures. ${ }^{[2]}$ The development of surgical care in these regions has halted or even regressed over the past two decades, often owing to the loss of young surgeons whose personal training needs are not met locally, resulting in ongoing migration to developed countries, the so-called brain drain. Major limiting factors in the development of surgical services are a lack of surgeons on the ground and of specialist surgical expertise and training in healthcare systems. ${ }^{[2]}$

Malawi, a landlocked country in sub-Saharan Africa, has the lowest physician-to-patient ratio in the world, where 1 doctor is responsible for 50000 patients. ${ }^{[4]}$ This shortage is particularly acute in surgery; in 2007, it was reported that 15 surgeons served this country, which has a population of 12 million people, ${ }^{[5]}$ and more recent data suggest that this alarming ratio remains unchanged. ${ }^{[6]}$ The Malawi Ministry of Health acknowledges that medical training institutions are not producing adequate numbers of graduates to meet the country's healthcare needs, and aims to address the critical staff shortages by piloting cost-effective higher-qualification training methods, such as e-learning, distance learning, applied and parttime learning. ${ }^{[7]}$
Our partner institutions have developed a pioneering approach to the delivery of vocational, academic training to the surgical profession in Malawi through an innovative, online Master's programme. The MSc in Surgical Sciences was established in 2007 by the University of Edinburgh and the Royal College of Surgeons of Edinburgh, and is designed to support trainees in the early years of surgical training. ${ }^{[8]}$ This 3-year, part-time programme uses a bespoke e-learning platform, hosting virtual case scenarios based on the most common surgical conditions, and a range of assessment activities, culminating in submission of a research dissertation (Fig. 1). All students enrolled on the MSc programme are in full-time employ as surgical trainees. Their parttime online learning activities are underpinned by in-the-workplace training, where they gain direct practical skills in surgery that, in turn, can be discussed and reflected upon in the virtual learning environment (VLE). Establishing what Garrison and Anderson ${ }^{[9]}$ term a 'community of inquiry', is central to the success of the students' educational experiences, and their model is shared with all of the e-tutors at the start of their teaching block. By delivering core academic content online, handson surgical training can be augmented without the need to remove trainees from their own country. Crucially, this transnational education has a minimal disruptive impact on surgical service delivery during the period of further study.

A number of successful educational programmes in surgery have been launched in African countries in recent years. Most notably, the Royal 


\section{Research}

College of Surgeons in Ireland (RCSI) and the College of Surgeons of East, Central and Southern Africa (COSECSA) have partnered to deliver a series of blended face-to-face and online programmes in surgical skills and pedagogical training of surgical trainers (http://www.rcsi.ie/cosecsa). O'Flynn et al. ${ }^{[10]}$ identified some of the challenges of these blended approaches, e.g. poor internet connectivity and the large distances between training facilities, making equity in participation potentially problematic.

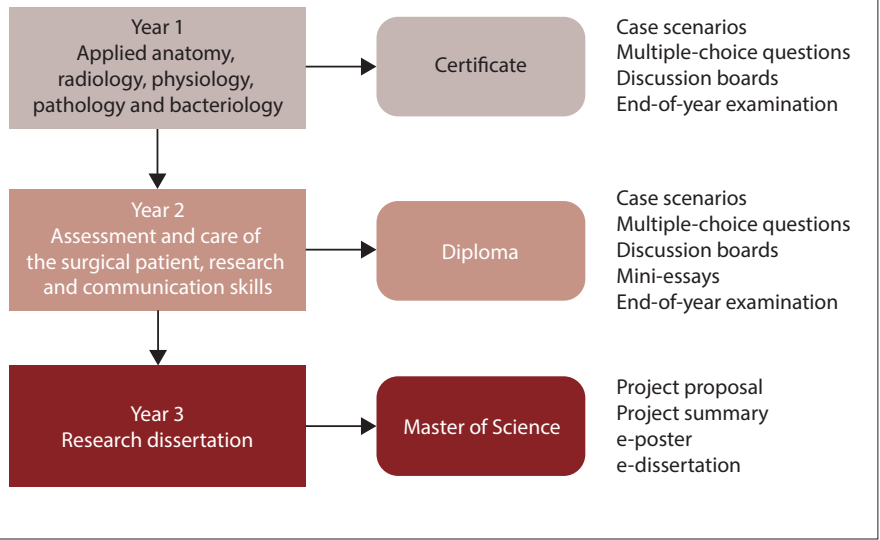

Fig. 1. Programme structure of the MSc in Surgical Sciences. Students are required to pass a variety of in-course and summative assessment tasks (right-hand column) to progress and attain a qualification.
In the current study, we addressed the research question, 'What is the perceived effectiveness of the fully online MSc in Surgical Sciences by students and training program supervisors??

Through sponsored ventures (Johnson and Johnson Citizenship Trust, Scottish Government International Development Fund, Physicians for Peace, Commonwealth Scholarship Commission in the UK, and Royal College of Surgeons of Edinburgh), a number of scholarships are awarded annually to surgical trainees in Malawi to cover tuition fees in full. Understanding how the MSc programme has benefited the Malawian trainees will assist us in refining the online content and delivery, and will help us to secure future scholarship funding.

\section{Methods}

To evaluate the perceived educational effectiveness of the online MSc for Malawian students, a web-based anonymous survey (Appendices ${ }^{\star}$ ) was issued to current students and graduates of the programme (distributed by PJWS), as well as training programme supervisors working in teaching hospitals in Malawi (distributed by EB). A 5-point Likert scale (strongly disagree, disagree, neither disagree nor agree, agree, strongly agree) was used for scoring purposes. The survey consisted of the same set of questions in two versions, one for supervisors and one for students, and focused around the potential and actual effectiveness of the programme (Table 1). The first question was designed to assess general attitudes on the use of online postgraduate surgical science programmes. Only supervisors whose trainees were current or former MSc students were invited to

Table 1. Mean Likert-scaled survey responses of clinical supervisors and Master's students, where $1=$ strongly disagree and $5=$ strongly agree

\begin{tabular}{|c|c|c|c|}
\hline Question & Mean & SD & $n$ \\
\hline \multicolumn{4}{|c|}{ Online postgraduate programmes in surgical sciences can improve the current surgical training programme in Malawi } \\
\hline Supervisor & $4.27^{\star}$ & 1.27 & 11 \\
\hline Student & $4.71^{*}$ & 0.47 & 17 \\
\hline \multicolumn{4}{|c|}{ The case-based scenarios in the MSc in Surgical Sciences can improve patient safety by providing a way to apply } \\
\hline \multicolumn{4}{|c|}{ knowledge virtually before practising in reality } \\
\hline Supervisor & $4.40^{*}$ & 0.70 & 10 \\
\hline Student & $4.29^{*}$ & 0.47 & 14 \\
\hline \multicolumn{4}{|c|}{ The case-based scenarios in the MSc in Surgical Sciences can improve decision-making skills } \\
\hline Supervisor & $4.40^{*}$ & 0.70 & 10 \\
\hline Student & $4.43^{*}$ & 0.51 & 14 \\
\hline \multicolumn{4}{|c|}{ The online, asynchronous discussion boards in the MSc in Surgical Sciences can improve communication skills } \\
\hline Supervisor & $4.10^{*}$ & 0.88 & 10 \\
\hline Student & $3.93^{*}$ & 0.62 & 11 \\
\hline \multicolumn{4}{|c|}{ Trainees'/my knowledge of the science underpinning surgery has improved since they/I have been on the MSc in } \\
\hline \multicolumn{4}{|c|}{ Surgical Sciences } \\
\hline Supervisor & 3.80 & 1.23 & 10 \\
\hline Student & $4.36^{*}$ & 0.63 & 14 \\
\hline \multicolumn{4}{|c|}{ Trainees'/my clinical decision-making skills have improved since they/I have been on the MSc in Surgical Sciences } \\
\hline Supervisor & 3.60 & 1.17 & 10 \\
\hline Student & $4.50^{*+}$ & 0.65 & 14 \\
\hline \multicolumn{4}{|c|}{ Trainees'/my communication skills have improved since they/I have been on the MSc in Surgical Sciences } \\
\hline Supervisor & 3.30 & 1.16 & 10 \\
\hline Student & $3.64^{*}$ & 0.74 & 14 \\
\hline \multicolumn{4}{|c|}{ You would recommend the MSc in Surgical Sciences programme to all junior surgical trainees in Malawi } \\
\hline Supervisor & $4.30^{*}$ & 0.95 & 10 \\
\hline Student & $4.93^{*}$ & 0.27 & 14 \\
\hline
\end{tabular}


complete the full survey beyond Question 1 . The survey ran for 3 weeks in semester 1 of the academic year 2017/2018, and excluded year-1 students because, as new intakes, they had only experienced 2 months of being on the programme. Furthermore, email questionnaires comprising free-text-style questions, collected since 2013 from Malawian students for scholarship quality assurance, were anonymised and re-purposed for analysis in the current study. Two reviewers (PJWS and DD) independently screened these student responses to identify common themes. Ethics approval, while sought from the Academic and Clinical Central Office for Research and Development (ACCORD) at the University of Edinburgh, was not required owing to the anonymous nature of the survey instruments. A one-sample $t$-test (SPSS Version 24.0, IBM Corp., USA) was used to identify whether responses to questions differed significantly from a neutral stance, i.e. agreed or disagreed. Differences between supervisor and student responses were compared using Student's $t$-test, assuming unequal variances (Microsoft Excel 2010, Microsoft Corp., USA). Malawian student performance was measured using two main metrics (in-course assessment and examination scores) and compared with that of other students in the same academic year. Differences between group means were identified using Student's $t$-test, assuming unequal variances (Microsoft Excel 2010, USA). Statistical significance was accepted when $p<0.05$. Data are expressed as mean (standard deviation) (SD).

\section{Results}

A total of 24 surgical trainees from Malawi have been admitted to the MSc programme since 2010, with 22 progressing to date (Fig. 2). This number represents $90 \%$ of the surgical trainees each year in Malawi. The first Master's student from Malawi graduated in November 2013. There have been 11 further successful graduates between 2014 and 2017, and 10 other students are currently on the programme. The demographics of Malawian students are similar to our international student cohort with regard to age (28 (3) v. 26 (3) years), but the majority of Malawian students are female (13:11) compared with the full MSc student cohort enrolled between 2010/2011 and 2017/2018, in which over two-thirds are male $(n=654 / 936)$.

Seventeen students (of 19 surveyed; 89\%) and 11 training programme supervisors (of 16 surveyed; 69\%) responded to the web-based, Likertscale surveys. Eleven student respondents are graduates and 6 are current students. Of the supervisors who responded, 10 have supervised current or former MSc students, and 1 has not. Responses were scaled from 1 (strongly disagree) to 5 (strongly agree). Table 1 shows that all student survey questions generated a positive response $(p<0.01)$. Student respondents had greater positive attitudes to the effectiveness of the online Master's programme compared with their clinical supervisors. All of the supervisor survey questions relating to the potential benefit of the MSc generated a positive response $(p<0.01)$, but supervisors' opinions on an actual improvement in their trainees' skills were not significantly different from neutral. The majority of students felt that the MSc had improved their knowledge of the science underpinning surgery (93\% agree or strongly agree) and clinical decision-making skills (93\% agree or strongly agree), but were more neutral with regard to an improvement in their communication skills (50\% agree or strongly agree). Students and supervisors would recommend the MSc to junior surgical trainees in Malawi.

Of the 19 Malawi-based students enrolled between 2010/2011 and 2016/2017, 15 (79\%) completed the free-text question-style written ques- tionnaire. Eight key themes around the benefits/disadvantages of the MSc in Surgical Sciences programme were identified (Table 2).

\section{Discussion boards}

Questionnaire feedback indicated that students appreciated the opportunity for discussion with surgical colleagues from other parts of the world. Students identified as a major advantage that the discussion boards allowed geographical differences in surgical practice to be explored, and encouraged students from the developed world to consider options available to surgeons from less-privileged areas. On this theme, a student noted:

'Regardless of where you are from, we are all exposed to the same material, which is very important for our profession because a doctor is supposed to be universal.' (Year 1 Malawian student)

The students stated that they enjoyed reading through the fellow students' posted discussions and that these stimulated them to try to read more widely on the issues raised. One student described feeling overwhelmed and experiencing a slight 'cultural shock' in the discussion boards in year 1 . For example, the student had rarely seen obese patients, and it was the first time she had ever heard the term 'bariatric (weight-loss) surgery'. Another student claimed:

'I have had a lot of "Aha! so this can be done!" moments.' (Year 2 Malawian student)

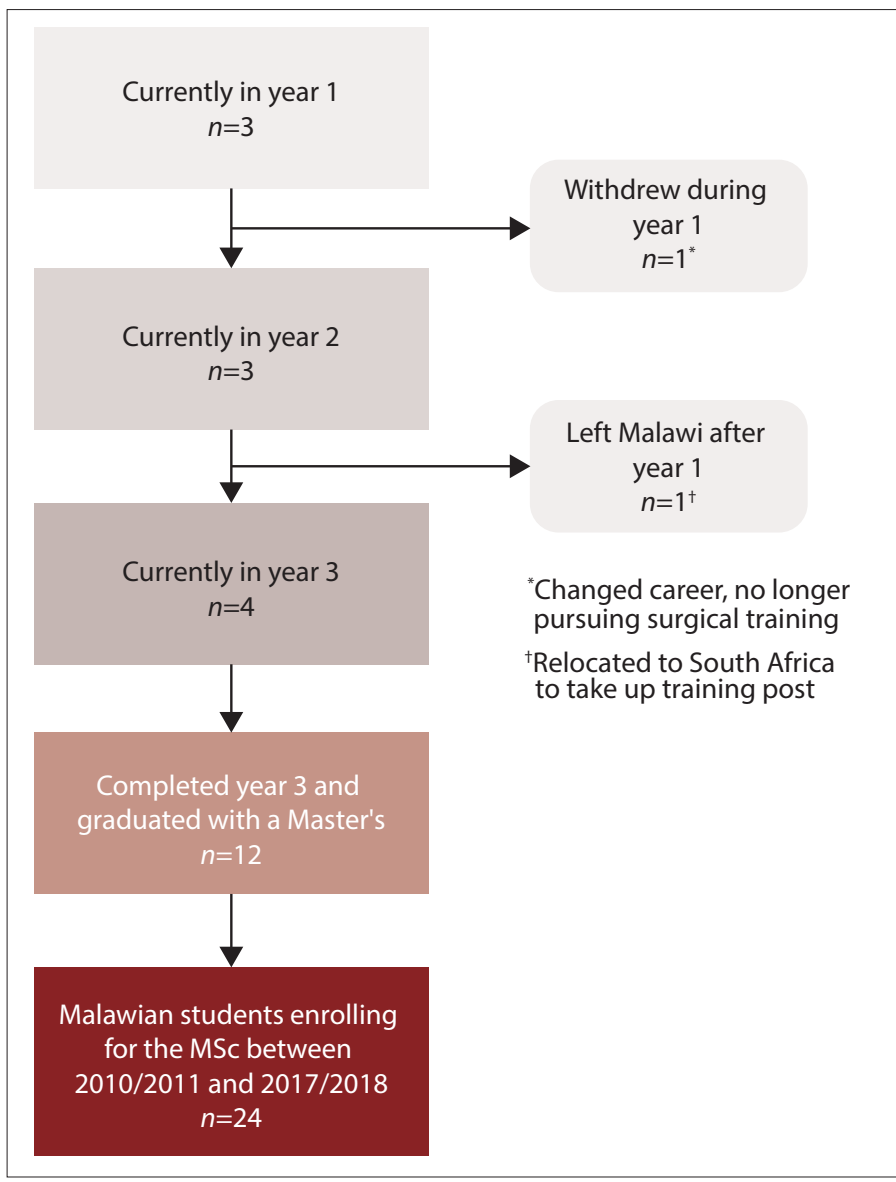

Fig. 2. Flowchart showing status and numbers of Malawian surgical trainees studying for the MSc in Surgical Sciences (November 2017). 
Table 2. Major themes relating to the MSc in Surgical Sciences identified from anonymised student questionnaire responses

\begin{tabular}{|c|c|c|c|}
\hline Benefits & $\%^{*}$ & Disadvantages & $\%^{*}$ \\
\hline $\begin{array}{l}\text { Interaction with international trainees, gaining different perspectives, } \\
\text { through discussion boards }\end{array}$ & 53 & $\begin{array}{l}\text { Sometimes difficult to relate UK-based clinical guidelines } \\
\text { (e.g. transplant surgery) }\end{array}$ & 13 \\
\hline Access to e-books/journals/course content and virtual patient scenarios & 27 & Internet provision slow/unreliable and costly & 40 \\
\hline Continuous assessment encourages regular study & 20 & $\begin{array}{l}\text { Time constraints on part-time study alongside full-time clinical } \\
\text { commitments }\end{array}$ & 53 \\
\hline Being taught by an international network of expert tutors & 47 & & - \\
\hline Relevant to professional examinations (e.g. MMed and COSECSA) & 20 & & - \\
\hline
\end{tabular}

It is clear that students consider themselves as part of an online community in which they learn from tutors and each other, as one student observed:

'The discussion boards are very helpful and I am comfortable making comment. There is so much that I am learning from the responses of trainees in other parts of the world and I am encouraged to read more when I see how much my fellow trainees know and post. The tutors are great; they really follow up our posts and correct us when we are not completely right.' (Year 1 Malawian student)

The only disadvantage relating to the feedback of the discussion boards was that Malawian students sometimes found it difficult to relate to clinical guidelines for procedures that are currently not conducted at their hospitals in Malawi, e.g. transplant, bariatric or laparoscopic surgery.

\section{Access to online content and virtual patient scenarios}

The structured presentation of the basic sciences integrated into interactive virtual patients was well received by students. The interactive model is provided by Labyrinth (http://labyrinth.mvm.ed.ac.uk), a tool for authoring and delivering case narratives that was developed at the University of Edinburgh. Labyrinth was created with the goal of supporting development of richly engaging, narrative medical cases that invites users to take control of their own decisions - and, by extension, their own learning - and develop the critical analytical skills to effectively face the consequences of those decisions. ${ }^{[11]}$

Trainees stated that they particularly valued access to electronic material. Students and e-tutors on the MSc programme receive access to an extensive University of Edinburgh e-library consisting of $>250$ surgical journals and textbooks, allowing surgeons from low- and middle-income countries (LMICs) to keep up to date with the latest medical advances. Previously, acquisition of knowledge was book-based, but the MSc programme encourages students to research web-based material, as one student explained:

'You get the opportunity to read all sorts of research papers, giving an update on certain conditions. I have learnt how to critically appraise an article and not just read a research paper as a "novel". (Year 3 Malawian student)

\section{Internet issues}

Perhaps not surprisingly, a major limitation of the programme related to information technology (IT) issues. While the VLE that was used to deliver the MSc in Surgical Sciences is accessible via smartphone, tablet and computer, the majority of students do not have good access to the internet at home and are reliant on often unreliable connections from the hospital where they work. The cost of installing broadband at home is prohibitive for most students, and speeds are often slow, which reduces the flexibility of our intended programme delivery. In 2016/2017, the costs of internet provision for the Malawian students - typically $~ 20 \%$ of a trainee surgeon's monthly salary - were met by the MSc programme, and will continue so going forward.

\section{Continuous assessment}

Students reported that they felt encouraged to study regularly throughout the year because assessment comprised both in-course assessment and summative examination components, in contrast to their professional membership examinations that do not include continuous assessment. Such a course structure helps to provide the necessary motivation to students, while acknowledging the time constraints of part-time study alongside fulltime clinical commitments. Notably, the majority of respondents cited these time constraints, something that is routinely expressed by their international peers on the MSc programme.

\section{International network of expert tutors}

From the feedback received, we know that interaction between tutors and fellow students on the discussion boards plays a key role in maintaining the Malawian students' engagement in the programme. The interconnected approach of the MSc in Surgical Sciences allows the sharing of knowledge between hundreds of international surgeons and trainees from up to 60 different countries. Malawian students praised the supportive online environment created by our tutors.

\section{Relevance to professional examinations}

Students considered course content to be useful in helping to prepare for other postgraduate training, such as the MMed in Surgery and the COSECSA membership examination, which share a similar curriculum to the first 2 years of the Edinburgh online Master's programme.

\section{Student performance}

Encouragingly, end-of-year performance (combined examinations and in-course assessment comprising discussion boards, multiple-choice questions, mini-essays) of Malawian trainees was not significantly different from that of the cohort average in the first 2 years of the programme (year 1: 58 
(17)\% v. 60 (11)\%; $p=0.60$; and year 2: 59 (6)\% v. 62 (13)\%; $p=0.36$ ) (Fig. $3 \mathrm{~A})$. However, data for the Master's year show that Malawian trainees scored less well than the cohort average when conducting a research project and producing an e-poster and research dissertation (59 (11)\% v. $68(10) \%$; $p<0.01)$ (Fig. 3A). Analysis of discussion board posts revealed that students from Malawi were more likely to post on weekly tutorial group discussions than their international peers (participation rate, i.e. number of discussion boards they were active in out of a total of 25, was $90(10) \%$ v. 69 (6)\%; $p<0.01$ ) (Fig. 3B). The marks for student activity in the asynchronous discussion boards - assigned by the tutor(s) who facilitated each board, based on quality and timeliness of posts - only comprise $15 \%$ and $10 \%$ of final marks in year 1 and year 2, respectively, accounting for the similarity of marks overall.

\section{Discussion}

This study describes the perceived educational effectiveness of the University of Edinburgh's pioneering online Master's programme in surgical sciences in one of the world's poorest countries. There was general agreement between students and trainee programme supervisors in Malawi that the MSc is a potentially useful educational resource. However, students were more positive about the potential and perceived impact of the programme on their development than supervisors' opinions of trainees enrolled for the MSc, but this is anticipated given students' personal expectations and inherent familiarity with the course content. Interestingly, in response to the statement, 'Online postgraduate programmes in surgical sciences can improve the current surgical training programme in Malawi', only one respondent disagreed, disclosing that no trainees working under their supervision are current or former students of the MSc programme. This suggests that there may be a bias against fully online educational resources for trainees unless surgeons have direct experience of such a programme. It should be emphasised that the MSc programme covers the academic science underpinning surgery, and is intended to complement the practical surgical skills gained from full-time, supervised surgical training posts.

The most common positive theme to emerge from the student free-text questionnaires was the beneficial nature of engaging with students and staff from other countries in the online discussion boards. These create an interactive online community that can reduce feelings of isolation associated with distance learning, ${ }^{[12,13]}$ and contribute to increased learning and student satisfaction. ${ }^{[14,15]}$ The MSc in Surgical Sciences encourages students to critically reflect on their day-to-day surgical practice in the context of recent advances, and engage in critical dialogue with peers and tutors. Malawian students were more likely to post on the boards than others in their cohort; this may be due to a sense of obligation as recipients of full-fee scholarship funding, as well as an appreciation of the interactions between fellow students and tutors.

Feedback from the Malawian students revealed a certain ambivalence to the international nature of the discussion boards; all were interested to learn about clinical practice in other parts of the world, but they sometimes found it difficult to relate to clinical guidelines for surgical procedures they are not familiar with. Although students may not be able to apply their own empirical evidence in discussions, such topics do challenge and extend their existing knowledge, and may prove relevant to future healthcare needs of LMICs. Equally, anecdotal feedback from our international student cohorts suggests that trainees from developed countries enjoy reading about the resourceful nature of peers in LMICs. Indeed, students can benefit from

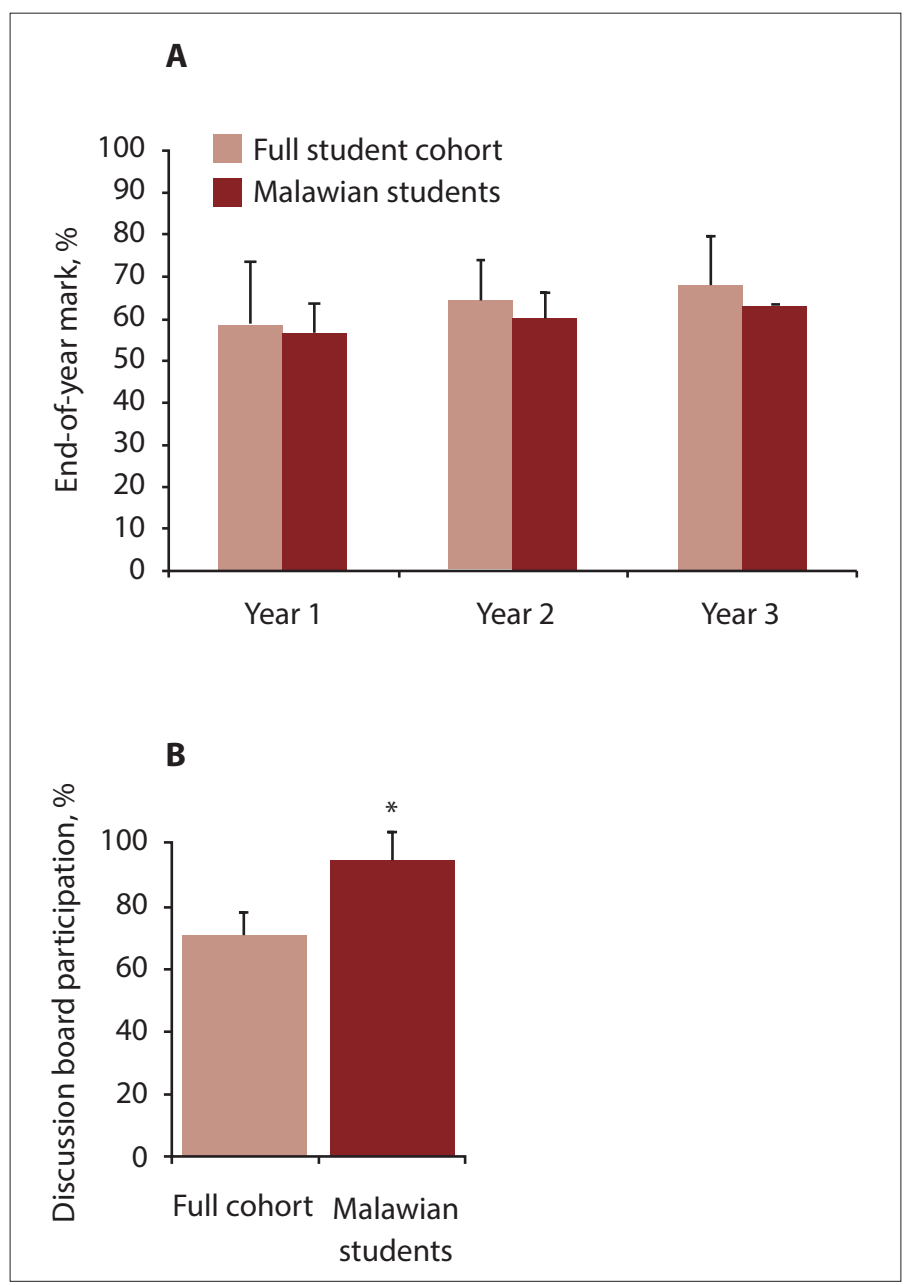

Fig. 3. (A) Comparison of academic performance between students enrolled for the MSc in Surgical Sciences from Malawi v. the cohort average, from 2010 to 2017. Average final percentage marks (mean (standard deviation (SD))) shown for students completing the course at the end of year $1(\mathrm{~N}=694$, full cohort; $\mathrm{n}=20$, Malawian); year $2(\mathrm{~N}=463 ; \mathrm{n}=16)$; and year $3(\mathrm{~N}=282 ; \mathrm{n}=12)$, reveal that there is only a significant difference between Malawian students and their respective cohorts in year 3 (59 (11)\% v. 68 (10)\%; p<0.01, unpaired Student's t-test assuming unequal variances). (B) Student level of participation on weekly, asynchronous, online discussion boards from 2010 to 2017. Percentage of boards active in (mean (SD)) shown for the full cohort $(\mathrm{N}=694)$ and Malawian students during years 1 and 2 $(\mathrm{n}=19)\left({ }^{*} \mathrm{p}<0.01\right.$, unpaired Student's $t$-test assuming unequal variances $)$.

contextualising the online content to their local practice. ${ }^{[16]}$ The online nature of the programme is especially important for trainees based in remote and rural areas, where interaction with peers from across the globe can ameliorate professional and social isolation. ${ }^{[2]}$

Limited internet and study time are clearly problematic for online students in Malawi. MSc content authors need to be mindful of limited bandwidths in LMICs when including video content or media requiring fast internet speeds. As such, any video content should provide standard, written transcripts. High costs of international bandwidth and limited availability mean broadband can be prohibitively expensive for students in Malawi. However, costs are expected to fall in the near future owing to completion of a national fibre-optic backbone that will provide global connectivity 
through a high-speed internet service. ${ }^{[17]}$ By meeting the costs of internet provision at a programme level, Malawian students have been able to study more flexibly, i.e. from home as opposed to remaining in their hospital workplace after hours to access the internet.

Over half of Malawian respondents cited time constraints on part-time study alongside full-time clinical commitments. Every student is appointed a personal tutor to provide academic and pastoral support throughout the year. This, together with the vocationally relevant course curriculum, helps students to manage their time effectively and view the MSc as a continuation of their in-the-workplace learning. This has ensured a high retention and success rate across all 3 years of the taught Master's. ${ }^{[8]}$

Malawian graduates of the MSc in Surgical Sciences have been invited to return to the programme as e-tutors and receive online training from the MSc team to assist them in this role. They subsequently play an important part in teaching some of the basic sciences to students $(n \sim 50)$ on the BSc General Surgery for Clinical Officers (COs) (non-medically qualified) in Malawi, as well teaching CO students ( $n>100$ annually) who are pursuing their Diploma in Clinical Medicine. Malawian undergraduate MBBS students ( $n \sim 80$ annually) are also beneficiaries of the knowledge imparted by MSc in Surgical Sciences graduates. These educational outcomes, along with research outputs generated from Master's dissertations, demonstrate the synergy of the online Surgical Sciences programme. Indeed, Vogt and Wang ${ }^{[18]}$ highlight the benefits of training local staff teaching to enhance the long-term impact and sustainability of educational initiatives in LMICs. The number of COs in Malawi far exceeds the number of doctors, and they provide most of the healthcare in the country. Post-basic education and training of this cadre of healthcare professionals have always been challenging, and the hope was that graduates of the online MSc would be equipped with the required qualifications and skills to teach those who provide the mainstay of clinical care in the district hospitals of Malawi. This hope has been realised, with the first graduate from the online MSc successfully organising and delivering anatomy training to first-year BSc General Surgery for COs in the College of Medicine, Blantyre, from 2013. This, in conjunction with larger student intakes to Malawi medical training institutions proposed by the Ministry of Health, will help to address the shortage of healthcare workers. Scale-up of doctors in LMICs requires initiatives to address both quantity and quality of the healthcare workforce. Frambach et al. ${ }^{[19]}$ describe how education programmes in sub-Saharan Africa should impart lifelong learning skills and equip learners with the motivation for self-directed development if the quality of healthcare professionals is to improve. We consider our online Master's programme as effectively encouraging students to engage in continuing professional development (CPD) through critical appraisal of the research literature, current clinical guidelines, opinions of peers and self-reflection to practise safe, evidence-based medicine. Although the Malawian students studying for the Edinburgh MSc achieved slightly lower marks in their research year than our international cohorts, each successfully conducted and completed their Master's dissertation and they are now equipped with the skills to pursue future research in their respective departments. Initiatives such as the Global Surgical Outcomes Collaboration (http://globalsurg.org/), which fosters regional, national and international surgical networks, will help surgeons from LMICs to become involved in global research projects.

The Global Health Workforce Alliance, launched in 2006 as a response to the global shortage of healthcare workers, is committed to greater access to and improved performance of the health workforce in LMICs. The Alliance has identified several key strategies that include developing innovative approaches to teaching in LMICs with state-of-the art teaching materials and continuing education through information and communications technology, and nurturing a new generation of academic leaders in LMICs with the support of experts from industrialised countries. ${ }^{[20]}$ Our innovative approach to educating surgeons in Malawi meets exactly these strategies, and can serve as a model for other LMICs. Qureshi et al. ${ }^{[6]}$ emphasised how postgraduate education, through online distance learning, can complement initiatives such as the surgical academic partnership between local hospitals in Malawi and international institutions, where collaboration is the key factor. ${ }^{\left[{ }^{[6]}\right.}$ Using an approach of collaborative training provided by clinicians from developing and industrialised countries means that trainee surgeons can remain in their home country as they attain their professional and academic milestones. This aspect is highlighted in the student feedback of our programme:

'I have been able to remain in Malawi to learn, while continuing to treat those who need me most.' (Malawian MSc graduate)

\section{Next steps}

Since the launch of our first online surgical postgraduate programme (MSc Surgical Sciences), a further 6 Master's programmes have been developed with the aim of supporting advanced surgical trainees in their intended specialty (http://www.essqchm.rcsed.ac.uk/), and it is likely that similar scholarship schemes to those running in the MSc Surgical Sciences will be initiated to support students from LMICs to study on the ChM programmes. Under the Commonwealth Scholarship scheme, students receive both full tuition fee funding and the participation costs of an outreach summer school to be held in Africa, aimed at supporting leadership and advocacy development. Our university is currently in discussion over widening access to some of the MSc content to meet educational and training needs. One possibility is to offer online surgical CPD opportunities to senior COs in Malawi to help to improve standards of healthcare in that country, with the potential to roll out similar models tailored to other under-privileged countries.

\section{Conclusions}

The Master's programme in Surgical Sciences has demonstrated its quality, relevance and global appeal by being taken up by $>1000$ trainees in 60 different countries worldwide. The growth in international recruitment, both in student numbers and international e-tutors employed, and the direct support offered by scholarships to students from LMICs, should improve surgical education in some of the poorest countries, including Malawi, over the coming years. By delivering this training while trainees stay in their own country, there is minimal impact on surgical service delivery. At the same time, it allows the sharing of knowledge among colleagues. Furthermore, this transnational approach prevents the brain drain that can occur when trainees travel abroad and fail to return. By training the MSc graduates to be effective teachers in their own countries, and encouraging them to pursue research activities, the impact of this education will spread far beyond enrolled students. Our online Master's programme will ultimately improve patient care in LMICs, as today's trainees become tomorrow's surgeons.

*Appendices available from the corresponding author on request. 
Acknowledgements. The authors wish to thank Johnson and Johnson Citizenship Trust, the Scottish Government International Development Fund, Physicians for Peace, the Commonwealth Scholarship Commission in the UK, and the Royal College of Surgeons of Edinburgh for their sponsorship of student bursaries, and the clinical supervisors and surgical trainees for their insightful feedback on the MSc programme, including Dr Lughano Kalongolera, who provided details on the teaching activities delivered by MSc graduates in Malawi.

Author contributions. PJWS: supervisor of the study, contributing to the planning, interpretation of results and writing of the manuscript; PJWS, DD: designed the questionnaire; PJWS, EB: distributed the questionnaire; and PJWS, DD: performed the data collection and reviewed students' responses. All authors contributed to the review of the literature, discussion of results and writing of the article.

\section{Funding. None.}

Conflicts of interest. None.

1. Alkire BC, Raykar NP, Shrime MG, et al. Global access to surgical care: a modelling study. Lancet Global Health 2015;3:e316-e323. https://doi.org/10.1016/s2214-109x(15)70115-4

2. Meara JG, Leather AJ, Hagander L, et al. Global Surgery 2030: Evidence and solutions for achieving health, welfare, and economic development. Lancet 2015;386:569-624. https://doi.org/10.1016/j.surg.2015.02.009

3. Shrime MG, Bickler SW, Alkire BC, Mock C. Global burden of surgical disease: An estimation from the provider 3. Shrime MG, Bickler SW, Alkire BC, Mock C. Global burden of surgical disease: An estimation
perspective. Lancet Glob Health 2015;3:S8-S9. https://doi.org/10.1016/s2214-109x(14)70384-5

perspective. Lancet Glob Health 2015;3:S8-S9. https://doi.org/10.1016/s2214-109x(14)70384-5
4. World Health Organization. Malawi: Factsheets of Health Statistics. 2016. http://www.aho.afro.who.int/profiles 4. World Health Organization. Malawi: Factsheets of Health Statistics. 2016. http://www.ah
information/images/d/d8/Malawi-Statistical_Factsheet.pdf (accessed 10 August 2018).

5. Lavy C, Tindall A, Steinlechner C, Mkandawire N, Chimangeni S. Surgery in Malawi - a national survey of activity in rural and urban hospitals. Ann R Coll Surg Engl 2007;89:722-724. https://doi.org/10.1308/003588407×20932 6. Qureshi JS, Young S, Muyco AP, et al. Addressing Malawis surgical workforce crisis: A sustainable paradigm for training and collaboration in Africa. Surgery 2013;153:272-281. https://doi.org/10.1016/j.surg. 2012.08.004
7. Malawi Ministry of Health. The health sector strategic plan, 2011 - 2016: Moving towards equity and quality2011. http://www.nationalplanningcycles.org/ (accessed 10 August 2018)

8. Smith PJW, Wigmore SJ, Paisley A, et al. Distance learning improves attainment of professional milestones in the early years of surgical training. Ann Surg 2013;258:838-843. https://doi.org/10.1097/sla.0000000000000211 9. Garrison DR, Anderson T. E-learning in the 21st Century: A Framework for Research and Practice. London: Routledge, 2003.

0. O’Flynn D, O’Flynn E, Deneke A, et al. Training surgeons as medical educators in Africa. J Surg Educ 2017;74:539 542. https://doi.org/10.1016/j.jsurg.2016.10.013

11. Begg M. Leveraging game informed learning in higher education. Med Teach 2008;30:155-158. https://doi. org $/ 10.1080 / 0142159070187404$

12. Mohamad M, Shaharuddin S. Online forum discussion to promote sense of learning community among group members. Int EducStudies 2014;7(13):61-74. https://doi.org/10.5539/ies.v7n13p61

13. Uijl S, Filius R, ten Cate O. Student interaction in small private online courses. Med Sci Educ 2017:27:237-242. https://doi.org/10.1007/s40670-017-0380-x

14. Rovai AP. Development of an instrument to measure classroom community. Internet High Educ 2002;5:197-211. hovai AP. Development of an instrument to me-

15. Croft N, Dalton A, Grant M. Overcoming isolation in distance learning: Building a learning community through time and space. J Educ Built Environ 2010;5:27-64. https://doi.org/10.11120/jebe.2010.05010027

16. Miliszewska L, Horwood J, McGill A. Transnational Education through Engagement: Students Perspective. Proceedings of the Informing Science and IT Education Conference, Pori, Finland, $24-27$ June 2003:165-173. http://citeseerx.ist.psu.edu/viewdoc/download?doi=10.1.1.6.352\&rep=rep1\&type=pd (accessed 10 August 2018).

17. BuddeComm. Malawi - telecoms, mobile and broadband - statistics and analyses: Executive summary. https:// www.budde.com.au/Research/Malawi-Telecoms-Mobile-and-Broadband-Statistics-and-Analyses (accessed 10 August 2018).

18. Vogt A, Wang S. Twelve tips for medical teaching in low-resource settings. Med Teach 2017;39(10):1029-1032. https://doi.org/10.1080/0142159X.2017.1327041

19. Frambach JM, Manuel BA, Fumo AM, van der Vleuten CP, Driessen EW. Students' and junior doctors' preparedness for the reality of practice in sub-Saharan Africa. Med Teach 2015;37:64-73. https://doi.org/10.31 09/0142159x.2014.920490

20. Global Health Workforce Alliance. 2012. The Global Health Workforce Alliance strategy 2013 - 2016: Advancing the health workforce agenda within universal health coverage. 2012:1-3. http://www.who.int/workforcealliance/ knowledge/resources/ghwastrat20132016/en/ (accessed 10 August 2018). 